\title{
The Role of Imagination in Decision-Making
}

BENCE NANAY

\begin{abstract}
The psychological mechanism of decision-making has traditionally been modeled with the help of belief-desire psychology: the agent has some desires (or other pro-attitudes) and some background beliefs and deciding between two possible actions is a matter of comparing the probability of the satisfaction of these desires given the background beliefs in the case of the performance of each action. There is a wealth of recent empirical findings about how we actually make decisions that seems to be in conflict with this picture. My aim is to outline an alternative model that is consistent with these empirical findings. This alternative model emphasizes the role imagination plays in our decisions: when we decide between two possible actions, we imagine ourselves in the situation that we imagine to be the outcome of these two actions and then compare these two imaginings.
\end{abstract}

\section{Introduction: The Belief-Desire Model}

Here is a question about the mind that is as general as it gets: what mediates between sensory input and motor output? The traditional answer is that it's beliefs and desires. Here is an example. I look out of the window and I see that it is raining outside. I form a belief that it is raining outside. I have a desire not to get wet and this, together with my further (instrumental) belief that the best way to avoid getting wet is to take an umbrella, leads to the forming of an intention to take an umbrella. This intention then triggers my action of taking my umbrella (see, e.g., Smith, 1987; Davidson, 1980; the origins of the account may go back to David Hume). On this model, it is beliefs and desires that mediate between sensory input and motor output.

This is the belief-desire model. It has been subject to various attacks. Animals and preverbal infants perceive and perform actions. Should we assume then that each time they perform a perceptually guided action, they go through the appropriate beliefs and desires? This would, according to many, over-intellectualize the mind (Hurley, 2001). Further, arguably, most of our own actions are also largely akin to those of animals: when we tie our shoelaces or brush our teeth, these actions are also unlikely to be mediated by propositional attitudes like beliefs and desires.

There are various alternatives to the belief-desire model when it comes to what mediates between sensory input and motor output. One quite radical alternative is enactivism. According to the enactivist, perception is the active exploration of one's

This work was supported by the EU FP7 CIG grant PCIG09-GA-2011-293818 and the FWO Odysseus grant G.0020.12 N. I am grateful for comments by Laura Gow, Margot Strohminger and two anonymous referees at this journal.

Address for correspondence: Centre for Philosophical Psychology, University of Antwerp Stadscampus-Gebouw D, D416, Grote Kauwenberg 18. 2000 Antwerp, Belgium and Peterhouse, Cambridge, CB2 1RD, UK.

Email: bence.nanay@ua.ac.be and bn206@cam.ac.uk

Mind \& Language, Vol. 31, No. 1 February 2016, pp. 127-143.

(C) 2016 John Wiley \& Sons Ltd 
environment, which can be described without talking about representations at all (Noë, 2004; Hurley, 1998; Gibson, 1966, 1979). The proponents of this approach avoid over-intellectualizing the mind by shifting the emphasis from mental to bodily activities. They emphasize the importance of bodily coping, that is, skills and abilities that are not really (or not exclusively) mental. This often takes the form of emphasizing the embodied nature of cognition. And this tends to amount to denying that perception is supposed to be described in representational terms.

According to this enactivist view, 'perception is not a process of constructing internal representations' (Noë, 2004, p. 178; see also Ballard, 1996; O’Regan, 1992). The main enactivist claim is that we have all the information we need in order to get around the world, out there, in the world. So we do not need to construct representations at all and, more specifically, we do not need perceptual representations. As Dana Ballard puts it, "the world is the repository of the information needed to act. With respect to the observer, it is stored "out there", and by implication not represented internally in some mental state that exists separately from the stimulus' (Ballard, 1996, p. 111; see also Brooks, 1991; Ramsey, 2007; Chemero, 2009; Hutto and Myin, 2013). Sensory input and motor output are so closely intertwined in a dynamic process that we do not need to posit any representations that would mediate between them.

A less radical alternative to the belief-desire model of what mediates between perception and action is the following: the mind is to be understood in terms of representations, but these representations are not conceptually or linguistically structured, nor are they uniquely human. They are better compared to the mental representations of the predator that make it possible for it to catch its prey. These representations are perceptual representations and inherently action-oriented. There are representations that mediate between perception and action, but they are not beliefs and desires. They are action-oriented representations (Clark, 1997; Mandik, 2005; Jeannerod, 1988, 1997; Jacob and Jeannerod, 2003; Nanay, 2011, 2012a, 2013).

What is crucial from our point of view is that both the enactivist and the action-oriented representation theorist aim to give an account of the motivation of those of our actions that are very simple, often automatic and that are similar to the actions of animals. They (explicitly or implicitly) make an exception for highly deliberative human actions, like deciding between two career paths.

Their general rhetoric is the following: most of our actions are similar to animal actions. These cannot be described with the help of the belief-desire model. Therefore, the belief-desire model needs to be discarded as a general theory of what mediates between perception and action. But the belief-desire model is very useful when we are trying to explain some complex, uniquely human deliberative actions. In other words, rather than discarding the belief-desire model altogether, we should limit its scope to decision-making and deliberative action. The aim of this article is to attack this last refuge of the belief-desire model.

I will take a fairly liberal view on what counts as decision-making. We can call any action 'decision-making' that involves choosing between two potential actions and that involves some degree of deliberation (this is not intended to be 
a definition as I don't think that the concept of deliberation is any clearer than that of decision-making). These two potential actions might be checking one box in a questionnaire rather than another, or pushing one button rather than another. They might also be decisions to marry one person rather than another, or taking up one job offer rather than another. Sometimes philosophers use the term 'decision-making' in a somewhat demanding manner. I don't. What I mean by it is basically what psychologists mean by it. Those who don't like my liberal use of this concept can read 'choice' instead of 'decision' in what follows (which is also the way psychologists often refer to the phenomenon I am after, see Tversky and Kahneman, 1981; Heath and Tversky, 1991).

What I take to be the central claim of the belief-desire model of decision-making is that decision-making is purely a matter of comparing beliefs and desires. More precisely, deciding between two possible actions is a matter of comparing the probability of the satisfaction of one's desires given one's background beliefs in the case of the performance of each action.

Most versions of the belief-desire model allow for this comparison (or for the beliefs/desires involved in it) to be non-conscious and/or non-explicit. But they are all committed to the claim that this comparison is about beliefs and desires. The only mental states required for this process are beliefs and desires (or other pro-attitudes, such as preferences). So a more appropriate way of labeling the 'belief-desire model' would be to refer to it as the 'pure belief-desire model'.

This way of thinking about decision-making is the official and very rarely questioned conceptual framework not only for philosophers, but also for empirical researchers on decision-making. The classic rational-choice theory literature uses this framework very explicitly, as does its main alternative, the prospect theory, although perhaps less explicitly (but see Fox and Tversky 1998; Heath and Tversky 1991; Fox and See, 2003; Wakker, 2004, where this assumption becomes more explicit).

The plan of the article is to argue that this way of thinking about decision-making is in conflict with some empirical findings about the way we actually make decisions (Section 2) and to outline an alternative account of decision-making, which focuses on imagination (Section 3). I then argue that this imagination-based account of decision-making is in a better position to explain the empirical findings about decision-making than the belief-desire model.

\section{Some Empirical Findings about Decision-Making}

I am not the first person to criticize the belief-desire model, not even in the context of decision-making (see some famous worries concerning the necessity and nature of beliefs involved in the process in Velleman, 2000; and Bratman, 1992). ${ }^{1}$ But my

1 There are further, more empirical problems for the proponent of the belief-desire model: The decision-making processes of non-human animals are subject to very similar biases as those of 
way of questioning the belief-desire model of decision-making involves drawing attention to its apparent conflict with some recent empirical results about the way we actually make decisions. Our actual decision-making is sensitive to order effects, to framing effects, and even to such odd environmental factors as the dirtiness of one's hands. And it is not clear how the belief-desire account can explain this.

Let's go through some of the most famous examples from the 'biases on decision-making' literature:

(a) Order effect: The order in which the questions are raised influences one's decision-making: the subject's decision will be different depending on whether task A comes before task B, or vice versa (Swain et al., 2008; Petrinovich and O'Neill, 1996).

(b) Framing effect: The way the question or problem is framed influences decision-making: if the subject has to decide between a certain amount of money or a 50 percent chance of twice that amount of money, the decision depends on whether the subject is about to lose or gain this sum (Tversky and Kahneman, 1981). The same decision problem, depending on whether it is framed as a gain or loss, yields very different outcomes.

(c) Previous (unrelated) experiences: Decision-making is also influenced by what-completely unrelated-experiences the subject had immediately before the decision-making process. Watching an episode of Saturday Night Live or a (boring) documentary on a small Spanish village has a significant impact on the decision made afterwards (about whether to push the fat man off of the footbridge to save five others, see Valdesolo and DeSteno, 2006).

(d) Ongoing (unrelated) experiences: Whether we are holding a cup of warm beverage or a glass of cold drink influences our decisions about other people (Williams and Bargh, 2008). Holding a teddy bear (as opposed to merely seeing one) also influences one's decisions about the social behavior of others (Tai et al., 2011).

(e) Environmental factors: The cleanliness of one's environment, and even of one's own hands, influences one's decision-making. Hand washing or cleansing, for example, influences our responses about what we would be willing to do in specific situations (Zhong and Liljenquist, 2006).

At first glance, these findings suggest a very different picture from the belief-desire model. Framing, previous experiences or environmental factors don't seem to have any influence on one's relevant beliefs and desires. Remember, according to the belief-desire model, our decision is based on comparing the satisfaction of our

humans (Caraco, 1981; Bateson, 2002; Chen et al., 2006; Hurly and Ossen, 1999; Marsh and Kacelnik, 2002; McCoy and Platt, 2005; Lakshminarayanan et al., 2011). If one tried to explain these risk-biases in terms of the belief-desire model of decision-making (i.e. in terms of comparisons between the satisfaction of desires given background beliefs), this would lead to a serious over-intellectualizing of the minds of very simple animals. 
desires given our background beliefs in the case of the performance of each action. And our background beliefs and desires are not altered by the film sketch we have just watched or by the teddy bear we are holding.

But this is much too quick. The proponents of the belief-desire model could push back in at least two different ways.

The first way in which the proponents of the belief-desire model could try to accommodate these empirical findings would be to insist on some fairly strong descriptive/normative distinction. The suggestion would then be that the belief-desire model is a normative model of how we should make decisions. It is not a descriptive model of how we actually make decisions. So, strictly speaking, all these empirical findings about how we actually make decisions are irrelevant to the normative model of decision-making. All the experiments I mentioned above could be explained away as deviations from the norm. There are different ways one can make this point. We could say that the belief-desire model describes rational decision-making, but we are not always, and not fully, rational beings. Or we could say that while the belief-desire model is the right description of System 2, the automatic and mainly unconscious System 1 often overrides System 2 (Sloman, 1996).

I take this way of trying to explain away the experiments about actual decision-making to be problematic for two reasons. First, the psychological and decision-science literature has long moved away from normative questions or questions about rational decision-making to descriptive questions about our actual decision-making (the locus classicus is Kahneman and Tversky, 1979; see also Bell et al., 1988, and Yaari, 1987 on the differences between these two projects). Thus, insisting on the primacy of the normative question would not exactly be a naturalistic move - although this consideration is unlikely to move those (very few) philosophers of decision-making who have anti-naturalistic leanings.

Second and more importantly, this normative/descriptive move makes the belief-desire model an incomplete account of actual decision-making. It would make the belief-desire model a good and complete account of ideal or fully rational decision-making, but describing fully rational decision-making is not in itself a particularly interesting project as fully rational beings don't exist (see Kahneman and Tversky, 1979). And if the belief-desire model wants to describe actual decision-making, it needs to be supplemented with an extra account that explains the deviations from the fully rational functioning of the belief-desire model. And these deviations will not be explained by beliefs and desires only-we need something else: we need to give up the 'pure' belief-desire model.

This would amount to tinkering with the general framework of the belief-desire model - by supplementing it with an account of what makes actual decision-making less than rational. That's one way to proceed: start out with the idealized case and add an account to explain the differences between the idealized and the actual case. This would not be my preferred option. I find it preferable to forget about the idealized case and start out with how we actually make decisions. A provocative analogy: we can understand perception by postulating a fully idealized maximally accurate and informative perceptual process that represents accurately the entire environs of the 
agent in three dimensions and in full detail. This is not the way our perceptual system works. So we can start out from this idealized case and add the limitations of our perceptual system (which is not always accurate and leaves out lots of details). Or we can start by examining our actual perceptual system. I prefer the latter route.

Nevertheless, regardless of which way we proceed in our attempt to understand actual decision-making, we need to depart from the belief-desire model; either in order to supplement it to cover actual decision-making, or in order to provide an alternative.

And here we need to address the second way of trying to accommodate the empirical findings about decision-making within the belief-desire framework. The general suggestion is that nothing should stop us from adding various extra elements to the existing belief-desire framework: perhaps the general structure of decision-making is the belief-desire structure, but it's not the end of the story. We can postulate some further mental states that are neither beliefs nor desires. And this extra mental state can influence either our background beliefs, or, more plausibly, the salience of our beliefs. So what changes in these examples would be the weight that we assign to our background beliefs. The suggestion would be the following: the warm coffee in my hand (or the film I have just watched) triggers a new mental state, which is still unlikely to change my beliefs themselves, but it can make me attend to certain beliefs or desires of mine and it can also make me ignore some others.

If we want to avoid postulating specific teddy-bear detector states or warm-coffee detector states, a more plausible option would be to postulate an affective state: ${ }^{2}$ touching the teddy bear triggers some kind of affective response, which is not triggered by merely looking at the teddy bear (or is triggered to a lesser extent). And this affective reaction makes some of our beliefs about other people (who have nothing to do with teddy bears) more or less salient. I take this to be probably the best way of explaining the aforementioned empirical findings within the framework of the belief-desire model (see Sinhababu, 2009, 2013). I can see two ways in which this proposal could be worked out, but both of them postulate not one but two new mental states that we have no reason to postulate other than salvaging the belief-desire model. If this newly added affective state is an emotion that is directed at the teddy bear, we would need some kind of representation that would connect the way the teddy bear is experienced to the way the people whose social behavior we are supposed to judge are experienced. As the emotion is about the teddy bear and not about the person we make the decision about, there needs to be some mental state that connects the two. Alternatively, if the affective state is some kind of mood (which I take to be different from emotions, since moods are not (necessarily) directed at a specific object), then we still need an extra mental state that would tell us how this mood state would influence our decision-making. There is nothing

2 This is not an armchair insight; there are more and more findings showing an important correlation between decision-making under risk and emotional arousal (Mellers et al., 1997; Lopes, 1987; Rottenstreich and Hsee, 2001). 
about a mood per se that would necessarily predispose us towards deciding one way or another. If holding the teddy bear puts us into a reassuring, nice and fuzzy mood, this says nothing in itself about how we should assess other people's social behavior. In both of these two ways of adding an affective state to the belief-desire arsenal, yet another mental state needs to be postulated. As both of these mental states (the affective and the extra, bridging one) can be unconscious, ${ }^{3}$ the only reason we postulate them is to defend the belief-desire model from these objections - a painfully ad hoc move.

The main aim of this article is to outline an alternative to the belief-desire account of decision-making. This is the topic I will now turn to.

\section{Imagination and Decision-Making}

The alternative to the belief-desire model of decision-making I want to explore in this article focuses on the concept of imagination. The suggestion is by no means new. In fact, we can read various passages in Marcel Proust's work as outlining a very thoroughly thought-out account of decision-making along these lines. Here is a brief but provocative statement: 'a mental picture which accompanies our choice may be said to be its motive'. ${ }^{4}$ Or, more specifically, 'Since my parents had told me that, for my first visit to the theatre, I should have to choose between these two pieces, I would study exhaustively and in turn the title of one and the title of the other (for those were all that I knew of either), attempting to snatch from each a foretaste of the pleasure which it offered me, and compare this pleasure with that latent in the other title. 5

But there are less literary accounts of decision-making in terms of imagination. The most important example is Jonathan Evans's theory of decision-making, according to which 'we need somehow to imagine the world (in relevant respects) as it might be following a particular choice or action under our control and decide how much we would like to be living in it. Moreover, we need to conduct a set of thought experiments for each possible action and compare their evaluations' (Evans, 2007, p. 12).

While I think that both Proust and Evans capture important aspects of the role imagination plays in our decision-making, I don't want to commit to all of their claims. Proust seems to suggest that the imagination is the only thing that is needed for decision-making and as we shall see, I think that there are other mental states involved in decision-making besides imagination. And Evans is very explicit that he is interested in how we should make decisions: how we should conduct thought

\footnotetext{
3 This is not something I take to be problematic in and of itself as I assume that emotions can be unconscious, see Winkielman and Berridge, 2004.

4 Proust, 1919 (Within a Budding Grove).

5 Proust, 1913 (Swann's Way).
} 
experiments for each possible action and compare their evaluations (see also Evans and Over, 2004, p. 12). As we have seen, my concern is how we do in fact make decisions.

So here is my fairly simple account of decision-making: when we decide between two possible actions, we imagine ourselves in the situation that we imagine to be the outcome of these two actions and then compare these two imaginings. The aim of this section is to expand on this idea and explain how it would work and what concept(s) of imagination it presuppose(s). I will then, in the next section, argue that this way of thinking about decision-making can account for the empirical results about decision-making in a straightforward manner.

Here is a toy example to demonstrate how the imagination-based account of decision-making would work (I used this example in Nanay, 2013, ch. 4). You need to decide between two academic jobs: one of them is at a prestigious university in a not very nice small town, and the other is at a not very prestigious university in a great city. How do you decide? The belief-desire model would suggest that you have some desires (or other pro-attitudes) about how you want to live the rest of your life, and you also have some background beliefs; deciding between the two jobs is a matter of comparing the satisfaction of these desires given the background beliefs for each of the two choices.

How would I describe the decision-making process in this example? When you decide between the two jobs, you imagine yourself in the situation that you imagine to be the outcome of your decision one way or the other. You imagine yourself at the prestigious university surrounded by great colleagues and doing excellent research in a sleepy small town, spending the evenings working or with colleagues. You also imagine yourself at the not so prestigious university, spending every night out in cool restaurants and at various cultural events, to return to teaching the next day among your mediocre colleagues and not-so-bright students. Then you compare these two imaginative episodes, and the one you prefer will be the course of action to follow.

It is important to emphasize that this account of decision-making relies on beliefs and desires (that is the difference, as I understand it, between Proust's account and mine). I have beliefs about big cities and small towns, about my potential colleagues and so on. And I have desires. And these beliefs (and desires) very much influence and constrain our imaginative episode. ${ }^{6}$ But, and this is the crucial point, beliefs and desires are not the only ingredients that are needed for making decisions - we also need an imaginative episode: we need to imagine the two potential outcomes and compare the two.

At this point, given that I explicitly admit to combining imaginative episodes and beliefs/desires in this account, one may wonder whether this would indeed give rise to a genuinely new model of decision-making, different from the belief-desire

\footnotetext{
${ }^{6}$ See Van Leeuwen, 2011, for an account of how beliefs constrain the imagination in general. 
model. Or is it just a way of tweaking the original belief-desire model with the help of some allusion to the imagination? While there is no talk of imagination in the core claim of the belief-desire model (about comparing the probability of the satisfaction of desires given background beliefs), this core claim doesn't exclude the possibility of enriching this explanatory scheme with the help of the imagination.

The crucial question is where imagination fits into this picture. I have argued that imagination is constrained by beliefs, but decision-making itself is a process that is not a matter of comparing probabilities of desire satisfaction given beliefs - in fact, it is a process of comparing imaginative episodes. But one could also combine imagination and belief the other way round: imagination in this picture would play the role of affecting our beliefs (or affecting which of our beliefs are salient). As imagination is widely held to have strong links to emotions (see Schroeder and Matheson, 2006; Van Leeuwen, 2011, 2016; Gendler and Kovakovich, 2005), imagination is a pretty good candidate for the extra mental state that the belief-desire model would need to postulate in order to account for the external influences described in the previous section. The teddy bear or the warm coffee trigger an imaginative episode, which, via an emotion pathway (see Van Leeuwen, 2011, 2016) changes the salience of some of our beliefs (and maybe even desires), which then explains why the teddy bear or the warm coffee have an influence on the way we compare the probabilities of the satisfaction of our desires given background beliefs. In this picture, the only role imagination plays is that it feeds into the traditional belief-desire model.

This way of combining imagination and beliefs/desires is indeed only a tweak on the original belief-desire model, and, as a result, it is also vulnerable to the worries I raised in the previous section (about the ad hoc nature of the postulation of these 'extra mental states'). But the way my own account combines imagination and beliefs/desires is very different. According to this new picture, decision-making is not the comparison of the probability of the satisfaction of desires given background beliefs. Decision-making is a matter of comparing imaginative episodes (even if these imaginative episodes are constrained by our beliefs).

And at this point, I need to say more about just what kind of imaginative episodes are involved in our decision-making. I will argue that the concept of imagination plays three distinct roles here: you imagine the person you imagine yourself to be in a situation you imagine to be the outcome of your decision.

The first of these is imagining oneself in a future situation. This kind of imaginative episode is often described as 'imagining from the inside.' But what does imagining from the inside mean? I take the most plausible way of analyzing imagining X from the inside to be imagining being in X's situation (see Williams, 1973; Smith, 1997; Darwall, 1998; Nanay, 2010b; the idea goes back to at least Adam Smith, see Smith, 1759/1976, p. 11). In the case of decision-making, $X$ is not another person; it is your future self. You imagine yourself in the situation you take to be the outcome of your decision. This is an instance of self-imagining.

The second role imagination plays in this model is the following. You do know some things about the situations you take yourself to be deciding between (that is, about living in a small college town, etc.) - this is why your beliefs can and do 
constrain this imaginative episode, as we have seen. But there are plenty of details in this picture of living in a small college town that need to be filled in, and where your knowledge cannot help any more (what you'll do on Saturday nights, what your house will be like, whether this or that potential colleague is sociable) - these details need to be filled in by your imagination. So you imagine yourself in a situation that you imagine to be the outcome of your decision.

The third role imagination plays in this model is a bit more complicated. The concept of imagining oneself in X's situation is notoriously ambiguous. It can be interpreted either as imagining being in X's situation, or as imagining being $\mathrm{X}$ in X's situation. This distinction is not new (Williams, 1973; Wollheim, 1973, 1974; Reynolds, 1989; Velleman, 1996), and it is not as straightforward as it may seem (see, for example, Gordon, 1995a, 1995b). In the present context, it matters a great deal whether I imagine myself - that is, my (present) self - in a future situation that I take to be the outcome of my decision, or whether I imagine my future self (or what I take to be my future self) in that situation. ${ }^{7}$

If you imagine your present self when you imagine yourself living in a small college town, this will not give you a particularly reliable way of deciding. It is irrelevant how your present self would feel in that situation, as your present self will never be in it. But if you imagine your future self in that situation, you would need to have some idea about how your future self may be different from your present self, which, again, requires imagination. You can imagine what your future self will be like, but you have no reliable information about what it will be like. Moreover, people seem to be particularly bad at this third imaginative episode: we systematically ignore the possibility that our future self could be different from our present self (see Quoidbach et al., 2013; see also the literature on affective forecasting).

These are the three roles imagination plays in the decision-making process. You imagine what you imagine to be your future self, being in a situation that you imagine to be the outcome of your decision. As none of these three episodes of imagination can be considered reliable, decision-making is extremely unlikely to yield the optimal outcome reliably.

It is important to emphasize that my claim is not that imagination in general is unreliable - it can be very reliable in some contexts (see Williamson, 2016; Kind and Kung, 2016). But the three imaginative processes involved in decision-making are not among those imaginative processes that are particularly reliable. And even if one of them were reliable, the unreliability of the other two is likely to yield a less than optimal outcome of the decision-making process.

It is important to emphasize that I am not claiming that we never make optimal decisions. We very often do, especially when it is about some decision-problem that concerns the near future, or one we encounter often-for example, where to go

\footnotetext{
7 By using the terms 'present self' and 'future self', I by no means want to commit to any particular account of the metaphysics of personal identity. The point, rather, is that one's preferences change over time, and one makes decisions differently at different stages of one's life.
} 
to get a decent cup of coffee in the neighborhood. But we have no reason to think that our decisions in general, and especially decisions that really matter to us, have much of a chance at yielding the optimal outcome.

And this takes us back to the contrast with the belief-desire model of decision-making. The belief-desire model takes rational and reliable decisionmaking to be the paradigmatic case, and it aims to explain deviations from this norm by appealing to various biases. The account I outlined proceeds in the opposite direction. It takes our actual, very unreliable, ways of making decisions to be paradigmatic. Its starting point is not the way we should make decisions, but the way we do in fact make decisions. And, as it turns out, the way we do in fact make decisions is extremely unreliable. ${ }^{8}$

\section{Conclusion: Imagination and the Empirical Findings about Decision-Making}

I have argued that the belief-desire account of decision-making cannot accommodate a number of important recent empirical findings about what influences our actual decision-making. Is the imagination-based account in a better position in this respect? Are the same empirical findings about decision-making I started out with consistent with the account I proposed above?

Does it influence your imaginative episodes that you are holding a cup of hot coffee or a teddy bear or that you've just watched a boring documentary? The answer is that it definitely does: it has been known for a long time that imagination is extremely sensitive to all kinds of external and seemingly irrelevant influences (see the locus classicus, Feingold, 1915; and see also more specific findings about the influences on mental imagery: Segal, 1972; Segal and Nathan, 1964; Nanay, 2010a, 2015; Raftopoulos, Forthcoming).

Here is an example: In the original Perky experiments, subjects were looking at a white wall and they were asked to visualize objects with their eyes open. Unbeknownst to them, hardly visible images of the visualized objects were projected on the wall. The surprising finding is that the subjects took themselves to be visualizing - while in fact they were perceiving (Perky, 1910). The standard interpretation of this experiment is that perception and visualization are phenomenally very similar-in fact they are, at least in these circumstances, indistinguishable. There are some controversies about this interpretation (Hopkins, 2012; Nanay, 2012b), but we can ignore these for present purposes.

\footnotetext{
8 In this respect, Jonathan Evans's account, in spite of its emphasis on the concept of imagination, is closer to the belief-desire model than to my own account. Evans believes that the decision-making process by means of hypothetical thinking is what happens in System 2, and it would be a fairly optimal way of making decisions this way if System 1 were not giving rise to all kinds of biases (see, esp., Evans and Over, 2004, p. 9). The method Evans describes is supposed to be close to being optimal. The decision-making process I talk about is not.
} 
In a variation of the original Perky experiment, the projected images were different from the ones the agents were asked to imagine and the result was that they ended up imagining a mixture of the object that was projected on the wall and the object that they were asked to imagine (Segal, 1972). For example, they were asked to imagine the skyline of New York City while, unbeknownst to them, they were gazing at an image of a red tomato. The result was that they imagined New York City at sunset (Segal, 1972, p. 206).

In other words, in the modified Perky experiment, the imaginative episode of visualizing the New York City skyline is sensitive to external, unrelated influences. But then if, as I suggested, our decision-making is a matter of imagining ourselves in various situations, it should not come as a surprise that decision-making is also sensitive to external, seemingly unrelated influences.

Finally, I want to address the question about just how radical this new imagination-based account of decision-making is. And I hope to show that it is not very radical at all. I want to give three examples from established research projects in the psychology of decision-making that have, for decades, implicitly used a framework that is more similar to the one outlined here than to the belief-desire model.

The first one is the literature on 'availability bias' (Kahneman and Tversky, 1973; Tversky and Kahneman, 1982), which, on closer inspection, really amounts to bias in imaginability. Tversky and Kahneman's original formulation is that 'there are situations in which people assess the [...] probability of an event by the ease with which instances or occurrences can be brought to mind' (1982, p. 9). It is difficult to see what could be meant by 'being brought to mind' if not imagination. My suggestion merely amounts to making this concept of imagination play a more central role in accounting for decision-making.

Second, one widely researched bias in decision-making is that we systematically overestimate the probability of certain events and underestimate the probability of other events. Most people widely overestimate the number of deaths resulting from homicide or fireworks, and underestimate the number of deaths caused by asthma or diabetes (Slovic et al., 1976). The popular-science explanation for this is that we read about and watch news footage of firework disasters all the time, but are much less aware of people dying of asthma. But this explanation needs to be supplemented by a view about the ways in which media exposure influences our decision-making. And a very straightforward view would be to say that we find it easier to imagine those scenarios that we have encountered (or read about) more often than those that we have never encountered (and rarely read about). So the difference is explained in terms of what is more imaginable. The same strategy could then be used to explain a wide variety of biases.

Third, here is yet another famous bias: most people want higher payoff in a lottery where there is one winning ticket out of 100 tickets if they know that all of the other 99 were bought by one and the same person, call her Jennifer (Walker, 1992; Wagenaar, 1988). Again, a simple explanation would be that it is easier to imagine 
that Jennifer has the winning ticket. The difference consists in what one can imagine easily.

Finally, a further way of emphasizing how the imagination-based account of decision-making is not all that radical would be to acknowledge that the two mechanisms (the imagination-based and the belief-desire one) often combine: we often take the results of imagination-based deliberation and use it in a belief-desire framework. Further, and even more interestingly, we can, and very often do, use the belief-desire framework for post-hoc rationalization of the decision-making, which in fact relied on imagination.

Centre for Philosophical Psychology
University of Antwerp
and
Peterhouse
Cambridge University

\section{References}

Ballard, D.H. 1996: On the function of visual representation. In K. Akins (ed.), Perception. New York: Oxford University Press, 111-31.

Bateson, M. 2002: Context-dependent foraging choices in risk-sensitive starlings. Animal Behavior, 64, 251-60.

Bell, D.E., Raiffa, H. and Tversky, A. 1988: Descriptive, normative, and prescriptive interactions in decision-making. In D. E. Bell, H. Raiffa, and A. Tversky (eds), Decision-making: Descriptive, Normative, and Prescriptive Interactions. New York: Cambridge University Press.

Bratman, M. 1992: Practical reasoning and acceptance in a context. Mind, 101, 1-16.

Brooks, R.A. 1991: Intelligence without representation. Artificial Intelligence, 47, 139-59.

Caraco, T. 1981: Energy budgets, risk, and foraging preferences in dark-eyed juncos (Junco hyemalis). Behavioral Ecology and Sociobiology, 8, 213-7.

Chemero A. 2009: Radical Embodied Cognitive Science. Cambridge, MA: MIT Press.

Chen, M.K., Lakshminaryanan, V. and Santos, L. 2006: How basic are behavioral biases?

Evidence from capuchin monkey trading behavior. Journal of Political Economy, 114, 517-32.

Clark, A. 1997: Being There. Cambridge, MA: MIT Press.

Davidson, D. 1980: Essays on Actions and Events. Oxford: Clarendon Press.

Darwall, S. 1998: Empathy, sympathy, care. Philosophical Studies, 89(2-3), 261-82.

Evans, J. St. B. T. 2007: Hypothetical thinking: Dual Processes in Reasoning and Judgement. Hove: Psychology Press.

Evans, J.St.B.T. and Over, D. 2004: If . Oxford: Oxford University Press. 
Feingold, G.A. 1915: The influence of suggestion on imagination. American Journal of Psychology, 26, 540-9.

Fox, C.R. and See, K.E. 2003: Belief and preference in decision under uncertainty. In D. Hardman and L. Macchi (eds), Thinking: Psychological Perspectives on Reasoning, Judgment, and Decision-making. New York: Wiley, 273-314.

Fox, C.R. and Tversky, A. 1998: A belief-based account of decision under uncertainty, Management Science, 44, 879-95.

Gendler, T. and Kovakovich, K. 2005: Genuinely rational fictional emotions. In M. Kieran (ed.), Contemporary Debates in Aesthetics. Oxford: Blackwell.

Gibson, J.J. 1966: The Senses Considered as Perceptual Systems. Boston, MA: Houghton Mifflin.

Gibson, J.J. 1979: An Ecological Approach to Visual Perception. Boston, MA: Houghton Mifflin.

Gordon, R.M. 1995a: Sympathy, simulation, and the impartial spectator. Ethics, 105, 727-42.

Gordon, R.M. 1995b: Simulation without introspection or inference from me to you. In M. Davies and T. Stone (eds), Mental Simulation. Oxford: Blackwell, 53-67.

Heath, C. and Tversky, A. 1991: Preference and belief: ambiguity and competence in choice under uncertainty, Journal of Risk and Uncertainty, 4, 5-28.

Hopkins, R. 2012. What Perky did not show. Analysis, 72, 431-9.

Hurley, S.L. 1998: Consciousness in Action. Cambridge, MA: Harvard University Press.

Hurley, S.L. 2001: Perception and action: alternative views. Synthese, 129, 3-40.

Hurly, T. and Ossen, M. 1999: Context-dependent, risk-sensitive foraging preferences in wild rufous hummingbirds. Animal Behavior, 58, 59-66.

Hutto, D. and Myin, E. 2013: Radicalizing Enactivism. Cambridge, MA: MIT Press.

Jacob, P. and Jeannerod, M. 2003: Ways of Seeing. The Scope and Limits of Visual Cognition. Oxford: Oxford University Press.

Jeannerod, M. 1988: The Neural and Behavioral Organization of Goal-Directed Movements. New York: Oxford University Press.

Jeannerod, M. 1997: The Cognitive Neuroscience of Action. Oxford: Blackwell.

Kahneman, D. and Tversky, A. 1973: Availability: a heuristic for judging frequency and probability. Cognitive Psychology, 5, 207-33.

Kahneman, D. and Tversky, A. 1979: Prospect theory: an analysis of decision under risk, Econometrica, 47, 263-91.

Kind, A. and Kung, P. (eds) 2016: Knowledge Through Imagination. Oxford: Oxford University Press.

Lakshminarayanan, V., Chen, M. K. and Santos, L.R. 2011: The evolution of decision-making under risk: Framing effects in monkey risk preferences. Journal of Experimental Social Psychology, 47, 689-93. 
Lopes, L.L. 1987: Between hope and fear: the psychology of risk. In L. Berkowitz (ed.), Advances in Experimental Social Psychology, vol. 20. New York: Academic Press, 255-95.

McCoy, A. and Platt, M.L. 2005: Risk-sensitive neurons in macaque posterior cingulate cortex. Nature Neuroscience, 8, 1220-7.

Mandik, P. 2005: Action oriented representation. In A. Brook and K. Akins (eds), Cognition and the Brain: The Philosophy and Neuroscience Movement. Cambridge: Cambridge University Press, 284-305.

Marsh, B. and Kacelnik, A. 2002: Framing effects and risky decisions in starlings. Proceedings from the National Academy of Sciences, 99, 3352-5.

Mellers, B. A., Schwartz, A., Ho, K. and Ritov, I. 1997: Decision affect theory: emotional reactions to the outcomes of risky options, Psychological Science, 8, 423-9.

Nanay, B. 2010a: Perception and imagination: amodal perception as mental imagery. Philosophical Studies, 150, 239-54.

Nanay, B. 2010b: Adam Smith's concept of sympathy and its contemporary interpretations. Adam Smith Review, 5, 85-105.

Nanay, B. 2011: Do we see apples as edible? Pacific Philosophical Quarterly, 92, 305-22.

Nanay, B. 2012a: Action-oriented perception. European Journal of Philosophy, 20, 430-46.

Nanay, B. 2012b: The philosophical implications of the Perky experiments. Analysis, 72, 439-43.

Nanay, B. 2013: Between Perception and Action. Oxford: Oxford University Press.

Nanay, B. 2015: Perceptual content and the content of mental imagery. Philosophical Studies, 172(7), 1723-36.

Noë, A. 2004: Action in Perception. Cambridge, MA: MIT Press.

O'Regan, K. 1992: Solving the 'real' mysteries of visual perception: the world as an outside memory. Canadian Journal of Psychology 46, 461-88.

Perky, C.W. 1910: An experimental study of imagination. American Journal of Psychology, 21, 422-52.

Petrinovich, L. and O’Neill, P. 1996: Influence of wording and framing effects on moral intuitions. Ethology and Sociobiology, 17, 145-71.

Proust, M. 1913: Swann's Way, C.K. Scott Moncrieff, trans. New York: Modern Library, p. 102.

Proust, M. 1919: Within a Budding Grove, C.K. Scott Moncrieff, trans. New York: Modern Library, p. 33.

Quoidbach, J., Gilbert, D.T. and Wilson, T.D. 2013: The end of history illusion. Science, 339, 96-8.

Raftopoulos, A. forthcoming: Late vision: processes and epistemic status. Frontiers in Perception Science. 
Ramsey, W.M. 2007: Representation Reconsidered. Cambridge: Cambridge University Press.

Reynolds S.L. 1989: Imagining oneself to be another. Noûs, 23, 615-33.

Rottenstreich, Y. and Hsee, C.K. 2001: Money, kisses, and electric shocks: on the affective psychology of risk, Psychological Science, 12, 185-90.

Schroeder, T. and Matheson, C. 2006: Imagination and emotion. In S. Nichols (ed.), The Architecture of Imagination. New York: Oxford University Press.

Segal, S.J. 1972: Assimilation of a stimulus in the construction of an image: the Perky effect revisited. In P. W. Sheehan (ed.), The Function and Nature of Imagery. New York: Academic Press, 203-30.

Segal, S.J. and Nathan, S. 1964: The Perky effect: incorporation of an external stimulus into an imagery experience under placebo and control conditions. Perceptual and Motor Skills, 19, 385-95.

Sinhababu, N. 2009: The Humean theory of motivation defended and explained. Philosophical Review, 118, 465-500.

Sinhababu, N. 2013: The desire-belief account of intention explains everything. Noûs, 47, 680-96.

Sloman, S.A. 1996: The empirical case for two systems of reasoning. Psychological Bulletin, 119, 3-22.

Slovic, P., Fischhoff, B. and Lichtenstein, S. 1976: Cognitive processes and societal risk taking. In J.S. Carroll and J.W. Payne (eds), Cognition and Social Behavior. Hillsdale, NJ: Erlbaum, 165-84.

Smith, A. 1759/1976: The Theory of Moral Sentiments, D.D. Raphael and A.L. Macfie, eds. Oxford: Clarendon Press.

Smith, M.A. 1987: The Humean theory of motivation. Mind, 96, 36-61.

Smith, M. 1997: Imagining from the inside. In R. Allen and M. Smith (eds), Film Theory and Philosophy. Oxford: Oxford University Press, 412-30.

Swain, S., Alexander, J. and Weinberg, J.M. 2008: The instability of philosophical intuitions. Philosophy and Phenomenological Research, 76, 138-55.

Tai, K., Zheng, X. and Narayanan, J. 2011: Touching a teddy bear mitigates negative effects of social exclusion to increase prosocial behavior. Social Psychological and Personality Science, 2, 618-26.

Tversky, A. and Kahneman, D. 1981: The framing of decisions and the psychology of choice. Science, 211, 453-8.

Tversky, A. and Kahneman, D. 1982: Judgments of and by representativeness. In D. Kahneman, P. Slovic and A. Tversky, (eds.), Judgment Under Uncertainty: Heuristics and Biases. New York: Cambridge University Press.

Valdesolo, P. and DeSteno, D. 2006: Manipulations of emotional context shape moral Judgment. Psychological Science, 17, 476-7. 
Van Leeuwen, N. 2011: Imagination is where the action is. Journal of Philosophy, 108, $55-77$.

Van Leeuwen, N. 2016: The imaginative agent. In A. Kind and P. Kung (eds), Knowledge Through Imagination. Oxford: Oxford University Press.

Velleman, D. 1996: Self to self. Philosophical Review, 105, 39-76.

Velleman, D. 2000: On the aim of belief. In D. Velleman, The Possibility of Practical Reason. Oxford: Oxford University Press, 244-81.

Wagenaar, W. 1988: Paradoxes of Gambling Behaviour. Hillsdale, NJ: Erlbaum.

Wakker, P.P. 2004: On the composition of risk preference and belief, Psychological Review, 111, 236-41.

Walker, M.B. 1992: The Psychology of Gambling. Oxford: Pergamon.

Williams, B. 1973: Imagination and the self. In B. Williams, Problems of the Self. Cambridge: Cambridge University Press, 26-45.

Williams, L.E. and Bargh, J.A. 2008: Experiencing physical warmth promotes interpersonal warmth. Science, 322, 606-7.

Williamson, T. 2016: Knowledge through imagination. In A. Kind and P. Kung (eds), Knowledge Through Imagination. Oxford: Oxford University Press.

Winkielman, P. and Berridge, K.C. 2004: Unconcsious emotion. Current Directions in Psychological Science, 13, 120-3.

Wollheim, R. 1973: Imagination and identification. In R. Wollheim, On Art and the Mind: Essays and Lectures. London: Allen Land, 54-83.

Wollheim, R. 1974: Identification and imagination. In R. Wollheim (ed.), Freud: A Collection of Critical Essays. New York: Anchor Press, 172-95.

Yaari, M. E. 1987: The dual theory of choice under risk. Econometrica, 55, 95-117.

Zhong, C-B. and Liljenquist, K. 2006: Washing away your sins: threatened morality and physical cleansing. Science, 313, 1451-2. 